une revue Gallia

Rhône-Alpes | 2009

\title{
Feurs
}

13, rue Edgar-Quinet

\section{Éric Thévenin}

\section{(2) OpenEdition \\ 12 Journals}

Édition électronique

URL : http://journals.openedition.org/adlfi/3501

ISSN : 2114-0502

Éditeur

Ministère de la culture

Référence électronique

Éric Thévenin, «Feurs », ADLFI. Archéologie de la France - Informations [En ligne], Rhône-Alpes, mis en ligne le 01 mars 2009, consulté le 19 avril 2019. URL : http://journals.openedition.org/adlfi/3501

Ce document a été généré automatiquement le 19 avril 2019

(c) Ministère de la Culture et de la Communication, CNRS 


\title{
Feurs
}

\author{
13, rue Edgar-Quinet
}

\section{Éric Thévenin}

\section{Identifiant de l'opération archéologique : 9595}

Date de l'opération : 2009 (EX)

1 Un diagnostic a été réalisé préalablement à la construction d'une piscine. C'est dans un environnement à vocation mixte (domestique et artisanale) que s'intègre l'intervention du 13 rue Quinet. Durant l'Antiquité, le secteur déjà quadrillé de rues orthogonales demeurait toutefois (aux vues des découvertes récentes) en marge du Forum Segusiavorum .L'intervention s'inscrivait ainsi à l'intersection de deux voies et dans l'angle sud-ouest d'un îlot dont on ignorait encore la vocation exacte.

2 Cette perspective est sensiblement modifiée par la découverte d'un important mur d'orientation nord-sud. Très différent des aménagements en matériaux périssables des fouilles adjacentes (bâtiment sur poteau au n 8 de la rue Edgar-Quinet) ce mur maçonné et profondément fondé complète de manière inattendue l'organisation de cette zone d'habitat. Parallèle à la voie nord-sud identifiée au $\mathrm{n}^{\circ} 8$ de la rue, ce mur de $0,60 \mathrm{~m}$ de large pourrait faire partie d'un important bâtiment en pierre (entrepôt, édifice périurbain?) ou constituer un aménagement linéaire (de type soubassement de portique ?) aménagé le long de la limite orientale de cet axe de circulation se dirigeant vers le centre ville (voie pénétrante).

$3 \mathrm{Au}$ sol, deux espaces distincts apparaissent de chaque côté du mur. À l'ouest, l'espace est occupé par des niveaux de sols stratifiés contemporains de la construction du mur. À l'est, l'espace visiblement extérieur ne comporte plus que des niveaux faiblement anthropisés. Une importante démolition observée à partir de $0,60 \mathrm{~m}$ de profondeur scelle les deux espaces.

4 Les productions céramiques et les types présents permettent de rattacher cet ensemble aux horizons 10 et 11 de Roanne entre 110-180 apr. J.-C. 
Thevenin Éric

INDEX

Thèmes : mur

Index géographique : Rhône-Alpes, Loire, Feurs

operation expertise (EX)

Index chronologique : IIe siècle apr. J.-C.

\section{AUTEUR}

ÉRIC THÉVENIN 